\title{
The Building Project
}

\author{
Jorge Luis Dieguez Salazar \\ Hidrofido \\ United Kingdom \\ hidrofido@gmail.com
}

\section{THE BUILDING PROJECT}

"The Building Project describes how our landscape continuously undergoes transformation and how our presence in nature influences and impacts on it. The impact has to be orderly and balanced, or the order of nature will be affected".

We do not leave this premise to other people. We have attempted to demonstrate and understand how we are part of this change. It is a necessity for human beings to be part of the change, and we have to be aware that our presence will not affect the harmony of the nature.

\section{PROJECT SUMMARY}

In the installation, we will project 3 to 4 different photographs of structures in different landscapes.

These structures begin to build from the beginning, when a spectator

arrives to the projection.

Step 1: We will use a white wall to project these photographs. We will attempt to frame the ratio of the projection on wall to show it like a picture. In

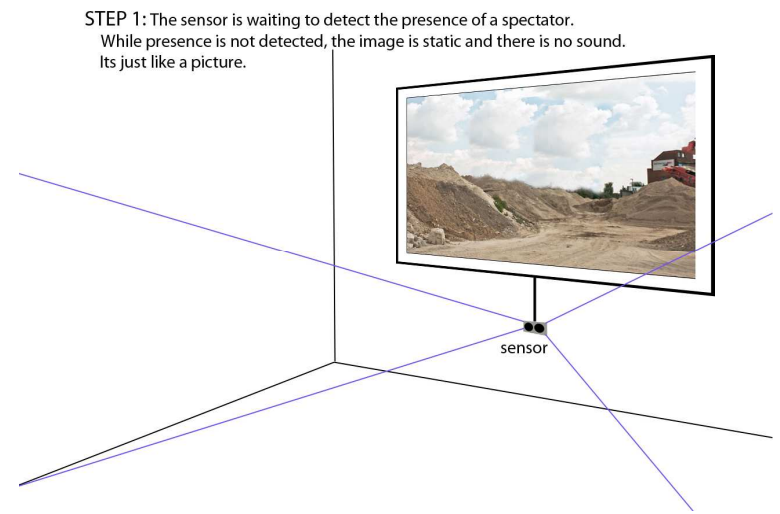

Jose Carlos Flores

OJOZ

Spain

josecarlosflorez@gmail.com

this projection will be first a photograph with only the landscape, without the structure.

Step 2: In the part below the wall we will put a sensor that detects the presence of a spectator and this is activated when a spectator is in front of the projection. When the sensor is activated, the sensor sends an impulse to a computer and the computer activates an animation that represents the building of the structure.

Steps 2, 3 and 4: The construction continues until the end as long as the spectator is present in front of the projection.

The installation includes and soundtrack. The sound increases while the construction of the structure develops. At the end the sound is extremely strident.

The sky begins static, and starts moving when the sensor detects a spectator.

This project is presented in a diptych format. Two projections from different landscapes with exactly the same line of depth are projected. The same soundtrack for the whole diptych is employed.

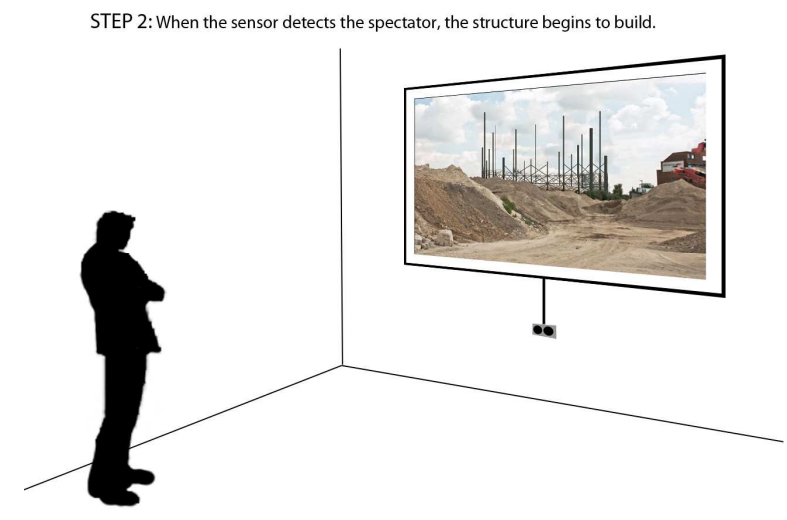


STEP 3: After the sensor active the structure construction, the construction continue and the sound makes louder.

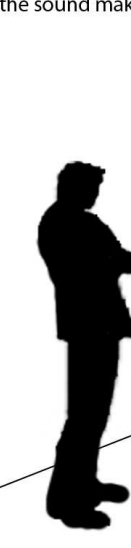

STEP 4: If the viewer continue seeing the image, will could see the entire structure.

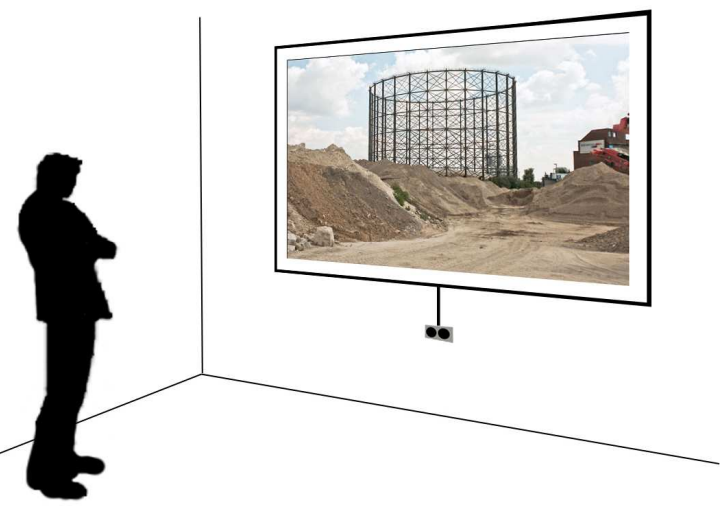

\section{HOW IT WORKS?}

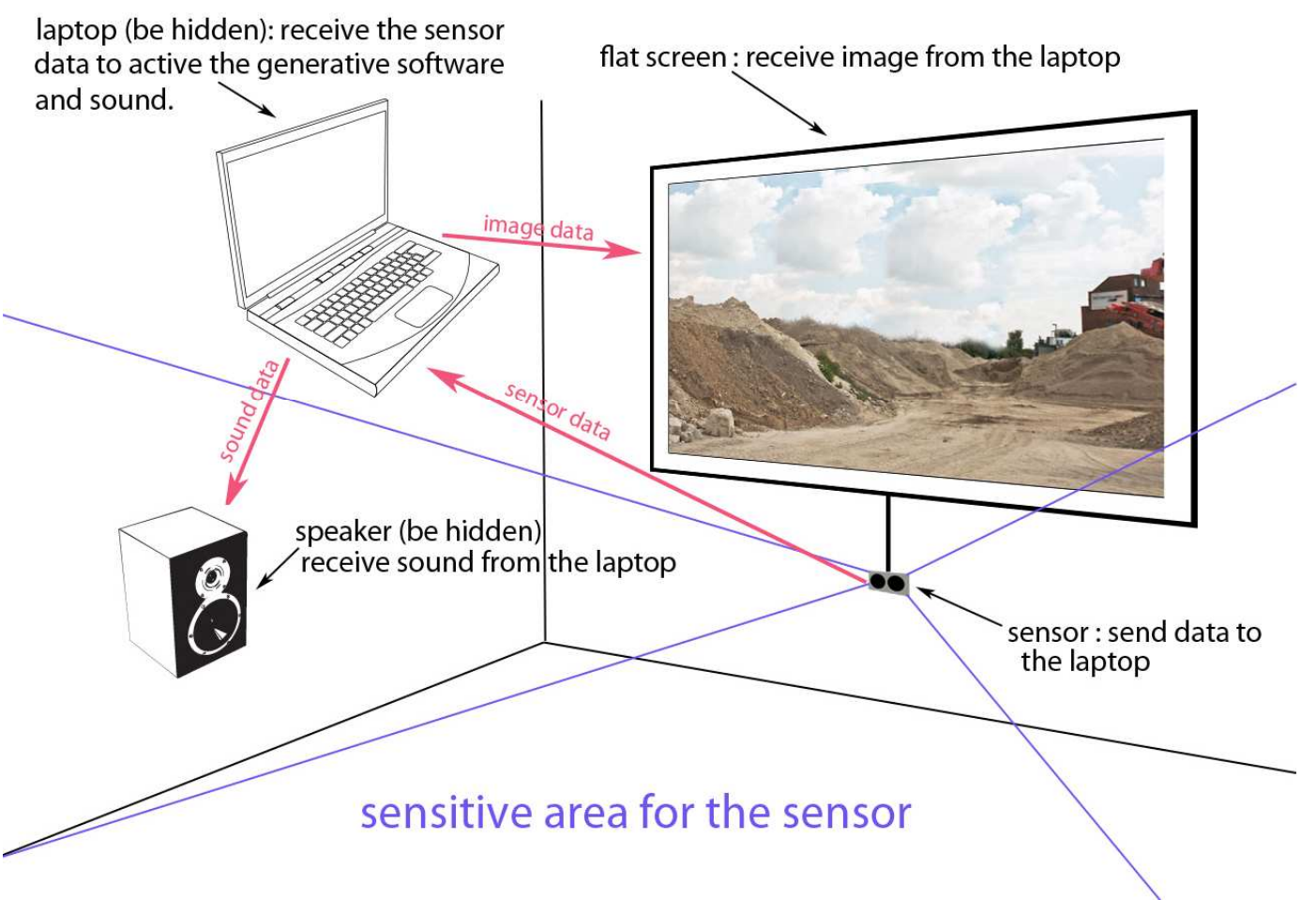

